\title{
Desafios da classe trabalhadora: Serviço Social na luta por condições de trabalho
}

\author{
Challenges of the working class: Social Work in the fight for \\ working conditions
}

\author{
Kleylenda Linhares da Silva* \\ Sâmya Rodrigues Ramos**
}

\begin{abstract}
Resumo - A contribuição da ação política do conjunto CFESS/Cress para a construção do projeto profissional pode ser analisada a partir de diversas frentes. Neste artigo, abordamos lutas por melhores condições de trabalho e como estas vêm repercutindo no cotidiano da classe trabalhadora, destacando, no âmbito do Serviço Social, a implementação da Resolução CFESS n ${ }^{\circ}$ 493/2006 e a importância da efetivação da Lei $n^{\circ} 12.317 / 2010$, que garante jornada de trabalho de $30 \mathrm{~h}$ semanais para assistentes sociais. Os dados aqui sistematizados foram elaborados a partir de pesquisas bibliográficas, documentais e de campo. Assim, na análise dos dados, fica claro que as profissionais conhecem a resolução; algumas mencionam a obtenção de conquistas a partir da mesma, como a consecução de sala para o Serviço Social. No tocante às $30 \mathrm{~h}$, as assistentes sociais destacam, entre outras coisas, que elas são bastante significativas para a qualidade de vida, proporcionando tempo livre.

Palavras-chave: condições de trabalho; serviço social; organização política; conjunto CFESS/Cress.
\end{abstract}

\begin{abstract}
How the political action of the CFESS/Cress partnership contributed to building the professional project can be analyzed from various fronts. This article deals with the struggles for better working conditions and how they have been affecting the daily lives of the working class. More specifically relating to Social Work, it highlights the implementation of the CFESS Resolution no. 493/2006 and the importance of the effectuation of Law n. 12.317/2010 guaranteeing a working journey of 30 hours/week for social workers. The data presented here were gathered from bibliographic, documental, and field researches. Thus, from the data analysis, it is clear that professionals know the resolution, some mentioning what was obtained from it, such as the achievement of room for Social Work. Concerning the working hours, the social workers highlighted, among other things, that it is very significant for life quality, providing free time.

Keywords: working conditions; Social Work; political organization; CFESS/Cress partnership.
\end{abstract}

\footnotetext{
* Mestra em Serviço Social. Professora Substituta do Curso de Serviço Social da Universidade do Estado do Rio Grande do Norte (UERN). Membro do Grupo de Estudos em Serviço Social, Trabalho, Direitos e Lutas Sociais (GESTULS). Correspondência: Rua: Maria Vieira Fernandes, no 1538, Abolição IV - Cidade: Mossoró-RN. Cep: 59.614-250. Email: $<$ kleylenda@hotmail.com>

** Doutora em Serviço Social pela Universidade Federal de Pernambuco (UFPE). Professora Adjunta do Curso de Serviço Social da Universidade do Estado do Rio Grande do Norte (UERN). Membro do Grupo de Estudos em Serviço Social, Trabalho, Direitos e Lutas Sociais (GESTULS). Correspondência: Rua José Negreiros, 21. Apto. 402, Centro - Cidade: Mossoró-RN. Cep:59.610-170. Email:<samyarr@uol.com.br>
} 


\section{Introdução}

Os assistentes sociais sofrem, assim como toda a classe trabalhadora, os rebatimentos da precarização do trabalho e da deterioração das suas condições nos espaços profissionais. A conjuntura, plena de desafios, exige luta e resistência para aplacar essa avassaladora onda de destruição de direitos. Como salienta Abreu(2008), é urgente a formação de alianças políticas visando à alteração da correlação de forças nos espaços de intervenção profissional e na sociedade. Isto se dá a partir do interesse das classes subalternas e da inserção profissional nos processos de luta pela conquista e garantia, com ampliação de direitos sociais fundados em princípios de democratização da gestão pública, universalização dos atendimentos e justiça social, no contexto das transformações capitalistas em curso.

Antunes (1999) argumenta que as consequências mais importantes das transformações ocorridas no processo de produção para o mundo do trabalho são: diminuição do operariado fabril típico do fordismo; aumento acentuado das inúmeras formas de precarização do trabalho; aumento expressivo do trabalho feminino no interior da classe trabalhadora; enorme expansão dos assalariados médios, especialmente no "setor de serviços"; exclusão dos trabalhadores jovens e "velhos" do mercado de trabalho; intensificação e superexploração do trabalho; e ocorrência de um processo de desemprego estrutural. Estas modificações, no mundo do trabalho, têm rebatimentos que incidem nas condições de trabalho e nas ações organizativas da classe trabalhadora e, em particular, dos assistentes sociais que são parte integrante deste segmento.

Nesse sentido, a organização política desta categoria e, em particular, a atuação do Conselho Federal de Serviço social (CFESS) e dos Conselhos Regionais de Serviço Social (Cress), nos últimos 35 anos, foram marcadas por uma intensa e frenética dinâmica de atividades em múltiplas frentes de luta. Assim, lutava-se contra as constantes perdas de direitos e a deterioração das condições de vida da classe trabalhadora, enorme ofensiva ideológica e prática para destruir os espaços de organização desta classe, marcas da sociabilidade do capital sob a hegemonia neoliberal.

Essas lutas gestam-se na conjuntura atual, marcada por intensas transformações socioeconômicas e políticas. As configurações deste cenário impactam, sem dúvida nenhuma, o mercado de trabalho, tensionando o cotidiano da intervenção profissional. Vão, sobretudo, a partir da década de 1990, com a hegemonia neoliberal, precarizar as relações e condições de trabalho. O exercício profissional sofre repercussões desta lógica destrutiva; por conseguinte, as possibilidades de materialização do projeto ético-político profissional são obstaculizadas.

Nesta perspectiva, abordamos os desafios e lutas da classe trabaIhadora no atual contexto de mundialização do capital, bem como a contri- 
buição da organização política da categoria de assistentes sociais em defesa de condições de trabalho, com destaque para algumas ações políticas do conjunto CFESS/Cress. Utilizamos resultados de pesquisas que objetivaram, em espaços sócio-ocupacionais diferenciados, apreender como se materializaram essas iniciativas no cotidiano profissional, quais sejam: efetivação da resolução CFESS no 493/2006, que dispõe sobre as condições éticas e técnicas para o exercício profissional, bem como a luta pela jornada de trabalho de 30 horas semanais para assistentes sociais (CFESS, 2006). Em nossa análise, destacaremos os rebatimentos destas estratégias políticas nas condições e relações de trabalho de assistentes sociais inseridos em diversas áreas de intervenção.

\section{Desafios e lutas da classe trabalhadora no contexto de mundialização do capital}

O cenário internacional, desde a década de 1970 e, mais explicitamente, nos anos 1980/1990, é marcado por uma crise estrutural, caracterizada pelo reordenamento do capital para recuperar seu ciclo produtivo. A ofensiva do capital destina-se a "reestruturar o padrão produtivo estruturado sobre o binômio taylorismo e fordismo, procurando, desse modo, repor os patamares de acumulação existentes no período anterior, especialmente no pós-45, utilizando-se de novos e velhos mecanismos de acumulação" (ANTUNES, 1999, p. 36).

A partir dos anos 1970, vivencia-se um quadro de crise estrutural, o que leva o capital a utilizar vários mecanismos de reestruturação, com destaque para a expansão da acumulação no interior da esfera financeira e a substituição do padrão taylorista e fordista pela "acumulação flexível" (CHESNAIS, 1996; HARVEY, 1999).

É importante salientar que o modo de produção capitalista gera, dentro de sua lógica, crises periódicas de superprodução de mercadorias (valores de troca). As principais causas das crises econômicas capitalistas são: a "superacumulação de capitais"; o "subconsumo das massas"; a "anarquia da produção"; a "desproporcionalidade" entre os diferentes ramos da produção, inerentes à propriedade privada e à economia mercantil generalizada; e a "queda da taxa de lucros". A função objetiva das crises de superprodução é a de constituir o mecanismo através do qual a lei do valor se impõe, apesar da concorrência capitalista (MANDEL, 1990).

Devido, sobretudo, a determinações econômicas e políticas e à redefinição do papel do Estado imposto pela necessidade de superação da crise do capital, a social-democracia e o socialismo real entraram em crise. Com isso, expandiu-se fortemente, notadamente na década de 1990, o projeto neoliberal. Assim, destaca-se, nesse contexto, que 


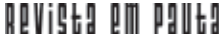

\} DESAFIOS DA CLASSE TRABALHADORA - SILVA, K. L.; RAMOS, S. R. \}

DOI: $10.12957 /$ rep.2015.21058

o triunfo da 'mercadorização', isto é, daquilo que Marx chamava de 'fetichismo da mercadoria', é total, mais completo do que jamais foi em qualquer momento do passado. O trabalho humano é, mais do que nunca, uma mercadoria, a qual ainda por cima teve seu valor venal desvalorizado pelo 'progresso técnico' e assistiu à capacidade de negociação de seus detentores diminuir cada vez mais diante das empresas ou dos indivíduos abastados, suscetíveis de comprar o seu uso. As legislações em torno do emprego do trabalho assalariado, que haviam sido estabelecidas graças às grandes lutas sociais e às ameaças de revolução social, voaram pelos ares, e as ideologias neoliberais se impacientam de que ainda restem alguns cacos delas. (CHESNAIS, 1996, p. 42).

Essa conjuntura de mundialização do capital, que revela as orientações ideo-políticas do neoliberalismo, traz como desdobramentos, dentre outras questões: o enaltecimento do papel do mercado em detrimento da ação pública; o enfraquecimento dos Estados Nacionais; a deteriorização das condições de trabalho e de vida da classe trabalhadora; e a difusão de um novo tipo de individualismo.

Nesse contexto, o capital e o trabalho assumem novas funções relacionadas aos processos de produção. As organizações sindicais, por exemplo, foram sendo cada vez mais "convencidas" para "trocar ganhos reais de salários pela cooperação na disciplinação dos trabalhadores de acordo com o sistema fordista de produção" (HARVEY, 1999, p. 129).

Retomando a tese básica da economia liberal desde Adam Smith, a proposta neoliberal defende que o mercado é a instância perfeita para resolver os problemas econômicos, argumentando que o que falta é implementá-lo em termos totais. A perspectiva neoliberal conclui que o mercado possui uma tendência imanente ao equilíbrio e que duas condições são essenciais para permitir uma aproximação com essa tendência: a propriedade privada e a liberdade de contrato. Quanto mais asseguradas essas condições, mais se caminha para o equilíbrio.

Nessa concepção, portanto, o mercado é reconhecido como solução para o problema econômico de base, como mecanismo único de coordenação das atividades econômicas de uma sociedade moderna. Mandel (1990, p. 117) analisa as consequências da economia de mercado, salientando que:

Nada ilustra melhor o caráter capitalista dessa famosa economia de mercado e suas conseqüências injustas e desumanas do que o espetáculo aflitivo de metade da humanidade passar fome não porque o mundo careça de produtos alimentares, mas porque a demanda solvível não pode seguir a física. Apesar da abundância de valores de

\footnotetext{
${ }^{1}$ Analisando as ideias do liberalismo, Teixeira (1998, p. 209) argumenta que o pensamento de Adam Smith vê a sociedade capitalista como uma "sociedade na qual o mercado deverá ser a instância suprema e intranscendível da vida humana".
} 


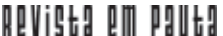

[ DESAFIOS DA CLASSE TRABALHADORA - SILVA, K. L.; RAMOS, S. R. ]

DOI: 10.12957/rep.2015.21058

uso, os valores de troca são inacessíveis, e algumas vezes até destruídos, condenando milhões de seres humanos a uma existência infrahumana.

Em vários balanços realizados sobre as consequências da implementação do neoliberalismo, constata-se que há diversos indícios da perversidade deste modelo na América Latina. Estes se expressam, sobretudo, nas seguintes questões: desemprego, aumento da pobreza e a pauperização das classes médias, colapso das economias regionais, incontável déficit fiscal, avassalador aumento da dívida externa e alienação da quase totalidade do patrimônio público via privatizações (BORON, 1999).

A perspectiva neoliberal obteve, também, uma grande vitória no terreno ideológico e moral, na medida em que disseminou desvalores ${ }^{2}$ individualistas, competitivos e egoístas, alardeando a falsa ideia de que não existe outra alternativa em termos de projeto societário. O fim da história, em contraposição direta ao projeto da modernidade, e o pensamento único são expressões desse fetiche que convenceu amplos segmentos, inclusive no universo do pensamento de esquerda, em nível mundial.

Outrossim, o neoliberalismo defende princípios que fundamentam uma visão de indivíduo e de sociedade pautada na defesa do modo de produção capitalista. Dessa forma, o neoliberalismo constitui-se numa teoria econômica que tenta dar resposta à crise do sistema capitalista de produção e que apresenta uma visão do indivíduo, da sociedade e do agir dos indivíduos no mundo. Portanto, expressando o reordenamento do capital para atingir seus objetivos em relação à expropriação do trabalho.

Nesse sentido, a fase atual do capitalismo é marcada por uma característica fundamental criada pelo seu próprio desenvolvimento: a internacionalização do sistema produtivo. O capital está mundializado, tendo o processo econômico ficado cada vez mais autônomo em relação aos Estados Nacionais. Analisando o sistema do capital, Mészáros (2002, p. 96) argumenta que este se constitui como a mais poderosa estrutura totalizadora de controle à qual os seres humanos já tiveram que se ajustar:

Não se pode imaginar um sistema de controle mais inexoravelmente absorvente - e, neste importante sentido, 'totalitário' - do que o sistema do capital globalmente dominante, que sujeita cegamente aos mesmos imperativos a questão da saúde e do comércio, a educação e a agricultura, a arte e a indústria manufatureira, que implacavelmente sobrepõe a tudo seus próprios critérios de viabilidade, desde as menores unidades de seu 'microcosmo' até as mais gigantescas empresas transnacionais, desde as mais íntimas relações pessoais

\footnotetext{
${ }^{2}$ Utilizamos a compreensão segundo a qual "pode-se considerar valor tudo aquilo que, em qualquer das esferas e em relação com a situação de cada momento, contribua para o enriquecimento daqueles componentes essenciais; e pode-se considerar desvalor tudo o que direta ou indiretamente rebaixe ou inverta o nível alcançado no desenvolvimento de um determinado componente" (HELLER,1989, p. 4-5).
} 


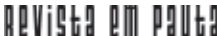

\} DESAFIOS DA CLASSE TRABALHADORA - SILVA, K. L.; RAMOS, S. R.

DOI: $10.12957 /$ rep.2015.21058

aos mais complexos processos de tomada de decisão dos vários monopólios industriais, sempre a favor dos fortes e contra os fracos.

O Brasil vem se integrando a essa nova lógica do capital em múltiplas dimensões. Tal integração ao processo de internacionalização do sistema produtivo assume contornos perversos e é visualizada em fenômenos como a privatização do Estado, a superexploração da força de trabalho, a dívida pública e o desemprego.

Esses são aspectos de fenômenos mais amplos engendrados pelo modo de produção capitalista. Em relação à dívida pública, particularmente à dívida externa, Mandel (1990) argumenta que a dívida crescente dos países ditos de Terceiro Mundo é um dos aspectos de um fenômeno muito mais amplo: a expansão do crédito como motor da economia do capitalismo tardio. Em relação ao desemprego, este autor argumenta que a análise feita por Marx, em $O$ capital, de que o capitalismo não pode sobreviver sem exército industrial de reserva, isto é, sem desemprego, é correta. Pois, sendo o regime capitalista um sistema de produção no qual o lucro e a acumulação de capital constituem os fins da atividade econômica, ele visa combinar o crescimento da produção material, um nível elevado de desemprego, a estagnação ou elevação muito moderada dos salários, a uma acelerada alta dos lucros e da acumulação de capitais.

A partir da década de 1990, com os governos Collor e Fernando Henrique, intensificou-se no país o receituário neoliberal. A marca do conturbado Governo Collor foi a implementação acelerada da estratégia neoliberal no país por meio das chamadas reformas estruturais; na realidade, o início da contrarreforma neoliberal no país. Diferentemente de Chile e Argentina, o Brasil vivencia um contexto de neoliberalismo tardio, neste período, deparando-se com a redemocratização em vias de radicalização e uma estrutura econômica mais sólida (BEHRING, 2003).

Condizentes com uma política de corte neoliberal, Collor iniciou e $\mathrm{FHC}$ deu forte impulso às propostas de desregulamentação, flexibilização, privatização acelerada e desindustrialização. Geraram, assim, dentre outras questões, a intensificação do processo de desmontagem dos parcos direitos trabalhistas, fruto de décadas de lutas da classe trabalhadora (ANTUNES, 1999).

Nesse período, observa-se uma ação ofensiva do metabolismo do capital através do projeto neoliberal, que se materializa, entre outros aspectos, no "desmonte" do Estado para o enfrentamento da questão social e no agravamento da deterioração das condições de vida das classes trabaIhadoras. Analisando o atual estágio da reestruturação produtiva do capital no Brasil, Antunes (1999) salienta que ocorrem: aumento das formas de superexploração da força de trabalho; mutações no processo tecnológico e informacional; flexibilização; desregulamentação e novas formas de gestão produtiva. Tais expressões indicam, dentre outras questões, que o fordismo, 


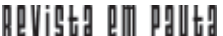

\} DESAFIOS DA CLASSE TRABALHADORA - SILVA, K. L.; RAMOS, S. R. \}

DOI: 10.12957/rep.2015.21058

ainda dominante, vem se mesclando com novos processos produtivos e com as formas de acumulação flexível oriundas do chamado toyotismo, que configuram as tendências do capitalismo contemporâneo. Chesnais (1996) salienta que o objetivo do toyotismo é obter a máxima intensidade do trabalho e o máximo rendimento de uma mão de obra totalmente flexível, contestando, cada vez mais, o direito de organização sindical. Tais processos incidiram na configuração, composição e condições de vida da classe trabalhadora, o que afetou o seu processo de organização.

A classe trabalhadora, diante desse processo, fragmentou-se, heterogeneizou-se e se complexificou ainda mais. Para Antunes (1999), um grande desafio hoje é compreender qual é a sua configuração e composição. Neste sentido, afirma este autor que ela compreende

a totalidade dos assalariados, homens e mulheres que vivem da venda da sua força de trabalho e que são despossuídos dos meios de produção. Essa definição marxiana e marxista me parece inteiramente pertinente, como de resto o conjunto essencial da formulação de Marx, para se pensar a classe trabalhadora hoje. (ANTUNES, 1999, p. 196).

Essa classe é, portanto, intensamente atingida pela profunda crise na sociedade, na qual a humanidade está mergulhada e que influencia todas as esferas da vida humana, incidindo de forma particular na política. Assim,

A política, forma sempre atual das contradições classistas, faz-se história. O Estado que foi sempre privatizado potencializa e garante a expansão máxima da classe dominante/dirigente. O Estado capitalista, para sua maior eficácia, tem necessariamente que aparecer como social, como articulador do conjunto da sociedade, como resumo qualificado do todo social. Nesse sentido ele buscou restringir permanentemente as formas associativas das classes subalternas em todas as suas formas de organicidade. (DIAS, 2002, p. 139).

A análise da política na sociedade capitalista demonstra que a reprodução do capital atinge todas as relações sociais e não apenas as relações de produção, submetendo-as à lógica mercantil. Bihr (1999, p. 144), analisando o processo de apropriação capitalista da práxis social, argumenta que "o processo de reprodução do capital procura apropriar-se da práxis social, produzindo uma sociabilidade, um modo de vida em sociedade a ele apropriado, por ser precisamente de acordo com as exigências de sua reprodução".

A classe trabalhadora é brutalmente atingida pelo processo de reprodução do capital. Mandel (1990) expõe que o resultado da ofensiva do grande capital contra os assalariados depende da interação de vários fatores, com destaque para as correlações de forças objetivas entre as classes, 


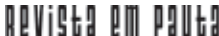

\} DESAFIOS DA CLASSE TRABALHADORA - SILVA, K. L.; RAMOS, S. R.

DOI: $10.12957 /$ rep.2015.21058

além do nível de organização e de consciência da classe trabalhadora e das reações das organizações de massa do movimento operário, sobretudo os sindicatos.

Apesar da complexificação da classe trabalhadora e da influência da crise nas várias esferas sociais, inclusive na política, as possibilidades da efetivação de um projeto de emancipação humana podem encontrar viabilidade a partir da mobilização dessa classe social.

Todo o amplo leque de assalariados que compreendem o setor de serviços, mais os trabalhadores 'terceirizados', os trabalhadores do mercado informal, os 'trabalhadores domésticos', os desempregados, os sub-empregados etc., pode somar-se aos trabalhadores diretamente produtivos e por isso, atuando como classe, constituir no segmento social dotado de maior potencialidade anticapitalista. (ANTUNES, 1999, p. 216).

No contexto recente, o processo de reestruturação produtiva do capital, desenvolvido em escala mundial a partir da década de 1970, forçou o Brasil a redefinir sua participação

na divisão internacional do trabalho, bem como sua (re)inserção no sistema produtivo global do capital, numa fase em que o capital financeiro e improdutivo expande-se e também afeta fortemente o conjunto dos países capitalistas. Por certo, a conjugação dessas experiências mais universalizantes com as condições econômicas, sociais e políticas que particularizam o Brasil tem gerado fortes consequêencias no interior do seu movimento social, em particular entre os movimentos operário e sindical. (ANTUNES, 1999, p. 237).

Na década de 1980 destaca-se, no âmbito da organização da classe trabalhadora no Brasil, além da construção do novo sindicalismo, a emergência de diversos movimentos sociais, que apresentam alguns traços comuns: seus objetivos situam-se fora da esfera do trabalho e da produção; foram caracterizados por uma desconfiança com o Estado e os partidos; desenvolveram uma ação crítica e contestatória, colocando aspectos particulares das condições gerais de existência resultantes da apropriação capitalista da práxis social; e exprimiram uma nova cultura política, centrada em novos valores.

Esses movimentos apresentaram diversos limites, dentre os quais destacam-se a não colocação da relação social do capital e das suas condições de reprodução, bem como o seu particularismo e isolamento em relação à luta de classe do proletariado. A separação entre estes movimentos e o movimento operário deve ser superada, pois é prejudicial para ambos na medida em que a luta anticapitalista deve se desenrolar simultaneamente dentro e fora do trabalho, visando à reapropriação da totalidade das condições sociais de existência (BIHR, 1999). 


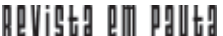

\} DESAFIOS DA CLASSE TRABALHADORA - SILVA, K. L.; RAMOS, S. R. \}

DOI: $10.12957 /$ rep.2015.21058

Os movimentos sociais vivenciaram, na realidade brasileira, um momento organizativo rico, na conjuntura dos anos 1980, que não se manteve na década seguinte devido a diversos fatores estruturais, conjunturais e próprios aos movimentos. Em relação ao movimento sindical dos trabalhadores, Antunes (1999) ressalta que, durante a década de 1980, o novo sindicalismo vivenciou um momento positivo, constatado a partir de diversos indicativos, tais quais: a ocorrência de uma enorme quantidade de movimentos grevistas desencadeados por variados segmentos de trabaIhadores; a expressiva expansão do sindicalismo dos assalariados médios e do setor de serviços; a continuidade do avanço do sindicalismo rural, em ascensão desde a década de 1970; o nascimento das centrais sindicais, com destaque para a Central Única dos Trabalhadores (CUT); a implementação de tentativas de organização nos locais de trabalho, por exemplo, por meio da criação de inúmeras comissões de fábrica; a efetivação de um avanço significativo na luta pela autonomia e liberdade dos sindicatos em relação ao Estado.

O conjunto destes elementos permite afirmar que, na década de 1980, ocorreu um contexto favorável ao novo sindicalismo, na contramão do que acontecia no âmbito de vários países capitalistas avançados, nos quais presenciava-se um quadro de crise sindical.

Nos anos 1990, como consequências das transformações no processo produtivo e da reestruturação das empresas, ocorreram: processo de desproletarização de contingentes operários; precarização e intensificação do uso da força de trabalho entre segmentos de trabalhadores no Brasil; retração da força de trabalho industrial; ampliação das distintas modalidades do trabalhado precarizado; e intensificação do processo de desmontagem dos direitos trabalhistas. Esta realidade, aliada à emergência de um sindicalismo neoliberal, arrefeceu e tornou mais defensivo o novo sindicalismo, fazendo com que o sindicalismo brasileiro se inserisse na onda regressiva internacional.

Antunes (1999) discute o aprofundamento do quadro crítico do sindicalismo brasileiro na década de 1990, argumentando que existem dois caminhos principais neste âmbito: o sindicalismo da Força Sindical, que preenche o campo sindical da nova direita, da sintonia com o capital globalizado; e a postura da Central Única dos Trabalhadores, que hegemonicamente vem adotando posicionamento de abandono de concepções socialistas e anticapitalistas, em uma perspectiva de acomodação dentro da ordem. A essa prática sindical da CUT estão vinculadas: a defesa da política de "parceria", as negociações com o patronato e a participação conjunta entre capital e trabalho, visando contribuir para o crescimento do país. Esta perspectiva sindical ajuda a reeditar práticas burocratizadas e de cúpula, que caracterizaram o sindicalismo brasileiro no pós-1930.

Dias (2002) salienta um aspecto importante para esta análise: o deslocamento do pensamento majoritário das esquerdas da esfera da 


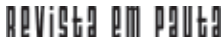

\} DESAFIOS DA CLASSE TRABALHADORA - SILVA, K. L.; RAMOS, S. R.

DOI: $10.12957 /$ rep.2015.21058

produção para o da circulação. Isto determinou a inflexão do projeto hegemônico das esquerdas para a defesa da democracia formal e da cidadania nos marcos da perpetuação do projeto capitalista, e não mais para a luta pelo socialismo.

Nessa conjuntura, alguns desafios estão postos para o movimento sindical e para o movimento dos trabalhadores em geral. Em relação aos sindicatos, Antunes (1999) sinaliza os seguintes desafios: romper a barreira social que separa os trabalhadores "estáveis" dos trabalhadores precarizados; reconhecer o direito de auto-organização das mulheres trabalhadoras; romper com todas as formas de neocorporativismo; romper com a tendência crescente à institucionalização e burocratização, que tem marcado o movimento sindical; reverter a tendência de reduzir o sindicato ao âmbito exclusivamente fabril, ao chamado sindicalismo de empresa; implementar a horizontalização, incorporando o vasto conjunto que compreende a classe trabalhadora hoje; e resgatar o sentido de pertencimento de classe. Em relação aos movimentos sociais dos trabalhadores em geral, afirma que estes devem

avançar na direção de um desenho societal estruturado a partir da perspectiva do trabalho emancipado e contrário ao capital [...]. Articular as ações que tenham como ponto de partida dimensões concretas da vida cotidiana e os valores mais gerais, que possam possibilitar a realização de uma vida autêntica, dotada de sentido [...]. É, portanto, necessário redesenhar um projeto alternativo socialista, que resgate os valores mais essenciais da humanidade. Um bom ponto de partida para tal ação é desenvolver uma crítica contemporânea e profunda à (des)sociabilização da humanidade sob o capital. Tendo, entretanto, como centralidade e eixo decisivos as ações sociais dos trabalhadores do campo e das cidades em seus movimentos sociais, sindicais e políticos que contestem e confrontam a lógica destrutiva do capital. (ANTUNES, 1999, p. 246-249).

Para esse autor, a luta contra o domínio do capital deve articular luta social e luta política num complexo indissociável. Rompendo, assim, com a dicotomia introduzida pelo capital entre ação econômica, realizada pelos sindicatos, e ação político-parlamentar, realizada pelos partidos. Nesse sentido, o maior mérito dos movimentos sociais de esquerda é reinventar novas formas de atuação autônomas capazes de articular e dar centralidade às ações de classe.

Dias (2002, p. 142-143) salienta que é necessário e urgente que as classes trabalhadoras assumam radicalmente seu protagonismo, sua autonomia e suas identidades, e formulem agendas e estratégias políticas no sentido de alterar a correlação de forças desfavorável.

Trata-se, portanto, de pensar e articular socialmente uma unidade dos diversos setores da classe organizados em sua múltipla inserção 


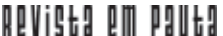

\} DESAFIOS DA CLASSE TRABALHADORA - SILVA, K. L.; RAMOS, S. R. \}

DOI: $10.12957 /$ rep.2015.21058

[...] Cabe aos movimentos sociais - compreendidos como unidade real das lutas das classes subalternas - avançar nessa clarificação político-ideológica e construir um projeto realmente democrático, classista, que tenha a marca do conjunto das classes subalternas, que traga a virtualidade do fim do Estado e das classes [...] Este é o projeto que se coloca para nós: sair dos limites do aqui e agora, da limitação da imediaticidade, reconstruir a política como atividade fundadora de uma nova ordem social para além do Capital.

Os desafios para a organização das classes trabalhadoras se ampliam nos anos 2000. No Brasil, são marcados, como analisam diversos estudiosos, pela hegemonia de governos eleitos a partir de um forte sentimento antiliberal, em contraposição ao terrível legado de FHC, mas que acabaram por aprofundar a ação neoliberal no país (BRAZ, 2007). Configura-se o Estado Social-Liberal, denominação utilizada por Castelo (2013), que preserva a essência da proposta neoliberal, mudando apenas alguns de seus elementos. A ideologia neodesenvolvimentista, defendida por este projeto político, legitima a lógica do capital, incidindo nas condições de vida, trabalho e organização das classes trabalhadoras, conforme ressalta Mota (2014, p. 30):

Na verdade, a despeito de todos os indicadores positivos que são ressaltados como resultado do desempenho da economia, permanecem intactos os pilares que dão sustentação à reprodução ampliada do capital. A superexploração do trabalho e as constantes denúncias sobre as condições de vida e de trabalho daqueles empregados no setor da construção civil - uma das maiores alavancas dos programas governamentais - são ilustrativas de que o rentismo e a concentração de renda caminham a contrapelo das reais condições de desenvolvimento social.

Nesse contexto, segmentos organizados das classes trabalhadoras aderem a este projeto, que tem se caracterizado, na sua relação com segmentos da sociedade civil, pela cooptação de entidades, organizações e movimentos sociais (a exemplo da direção política assumida pela CUT e pela UNE) (NETTO, 2007).

Diversos movimentos e entidades, entretanto, têm garantido sua autonomia e atuado na lógica de dar centralidade às ações de classe, na perspectiva de articulação com outros sujeitos coletivos. É a partir desta concepção que se desenvolve a direção hegemônica da organização política dos assistentes sociais, através da ação política das suas entidades organizativas. Assim, destacamos aqui a atuação do Conselho Federal de Serviço Social, ressaltando suas lutas em torno de melhores condições de trabalho para a categoria profissional e toda a classe trabalhadora.

Dentre outras frentes de atuação, a ação política do CFESS tem se direcionado para a defesa das condições de trabalho. Portanto, em con- 


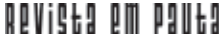

\} DESAFIOS DA CLASSE TRABALHADORA - SILVA, K. L.; RAMOS, S. R.

DOI: $10.12957 /$ rep.2015.21058

sonância com a direção do projeto ético-político profissional, considera os desafios contemporâneos presentes nas condições e relações de trabalho, no contexto de defesa dos interesses da classe trabalhadora na perspectiva da construção de um projeto societário anticapitalista (SANTOS, 2010).

Nesta perspectiva,

A luta por melhores condições de trabalho para assistentes sociais é um compromisso histórico do Conjunto CFESS/CRESS e se insere na luta pelo direito ao trabalho com qualidade para toda a classe trabalhadora, conforme estabelece nosso Código de Ética. Nossa luta pauta-se pela defesa de concurso público, por salários compatíveis com a jornada de trabalho, funções e qualificação profissional, estabelecimento de planos de cargos, carreiras e remuneração em todos os espaços sócio-ocupacionais, estabilidade no emprego e todos os requisitos inerentes ao trabalho, entendido como direito da classe trabalhadora. A Resolução CFESS N 493/2006 é um instrumento dessa luta ao estabelecer condições éticas e técnicas para o exercício da profissão. (CFESS, 2008).

Algumas pesquisas socializadas em artigos, que analisam as condições de trabalho de assistentes sociais, a exemplo de Prédes (2002) e Santos et al. (2010), atestam a importância das iniciativas do conjunto CFESS/ Cress para a fiscalização e defesa do exercício profissional. Isto, por meio de "várias atividades que perpassam o debate das condições de trabalho, mas também da capacitação profissional e da organização política da categoria" (SANTOS et al., 2010, p. 173).

Nesse sentido, discutiremos, a seguir, iniciativas do conjunto CFESS/Cress e suas repercussões no cotidiano de trabalho de assistentes sociais, tomando como referência pesquisas realizadas sobre essa temática.

\section{Luta por condições éticas e técnicas: efetivação da Resolução no 493/2006}

Dentre as estratégias políticas construídas pelo conjunto CFESS/ Cress em defesa de melhores condições de trabalho, na perspectiva de contribuir para a materialização do projeto profissional, temos a publicação de inúmeras resoluções. Em consonância com o Código de Ética e a Lei de Regulamentação da Profissão, são discutidas e aprovadas democraticamente nos fóruns deliberativos deste conjunto. Dentre estas, destacamos, para esta análise, a Resolução no 493/2006, que dispõe sobre as condições éticas e técnicas de trabalho, como relevante instrumento que objetiva a defesa de meIhores condições de trabalho, bem como a garantia do sigilo profissional, importante prerrogativa inscrita no Código de Ética desta categoria (CFESS, 2006).

A referida resolução foi elaborada com o intuito de constituir legalmente mais um instrumento de reivindicação para a melhoria das con- 


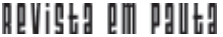

\} DESAFIOS DA CLASSE TRABALHADORA - SILVA, K. L.; RAMOS, S. R.

DOI: 10.12957/rep.2015.21058

dições de trabalho de assistentes sociais. Por isso, preconiza "a necessidade de instituir condições e parâmetros normativos, claros e objetivos, garantindo que o exercício profissional do assistente social possa ser executado de forma qualificada ética e tecnicamente" (CFESS, 2006).

Ao verificar o conteúdo desta resolução, podemos concluir que, sem dúvidas, constitui-se como um instrumento potencializador da defesa das condições de trabalho de assistentes sociais, na perspectiva de contribuir para a garantia dos pressupostos éticos profissionais, com destaque para o sigilo, pois "a questão do 'sigilo profissional' tem sua previsão clara e incontroversa no Código de Ética do Assistente Social" (TERRA, 2013, p. 1).

Nas reflexões desenvolvidas no Código de Ética do assistente social, Terra (2013) explica o sigilo profissional em duas vertentes: como direito e como obrigação. É uma obrigação profissional prevista no Código de Ética, corpo normativo que versa sobre regras negativas e obrigatórias. É também um direito e, como tal,

deverá ser respeitado por todos os outros que se relacionam com o assistente social na sua atividade profissional, seja qualquer superior hierárquico, empregador, patrão, enfim qualquer um que nas relações de poder possa ou pretenda interferir na atividade profissional do assistente social, ou impor regras de conduta incompatíveis com o sigilo profissional. (BARROCO; TERRA, 2012, p. 205-206).

Terra (2013) argumenta, ainda, que o sigilo profissional visa, também, à proteção da intimidade e privacidade das pessoas. Adota, na sua argumentação, a expressão "direito à intimidade e a privacidade" para designar

todos os meios que o sistema constitucional e cível disponibiliza para a defesa e proteção judicial dos direitos fundamentais relacionados - ao que hoje se denomina - 'autodeterminação informativa' dos dados relativos à intimidade da vida privada, que ficou conceituado como o direito dos indivíduos de 'decidirem por si próprios, quando e dentro de quais limites seus dados pessoais podem ser utilizados'. Considera-se que a 'autodeterminação' é direito fundamental do cidadão, inscrito na esfera do direito geral de personalidade, protegido pela Constituição Federal e pela Declaração dos Direitos humanos. Neste contexto se insere o direito e a obrigação ao sigilo profissional. (TERRA, 2013, p. 3-4).

Nesta perspectiva, analisa que, mesmo sendo um direito do assistente social e dos usuários, o sigilo, muitas vezes, é violado em decorrência das condições de trabalho existentes nas instituições empregadoras.

Embora a manutenção do sigilo seja um direito do assistente social, muitas vezes o respeito a tal garantia é violado pelas condições e estrutura do ambiente de trabalho, da estrutura física da sala onde 


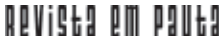

\} DESAFIOS DA CLASSE TRABALHADORA - SILVA, K. L.; RAMOS, S. R. \}

DOI: $10.12957 /$ rep.2015.21058

está instalado o Serviço Social, que por vezes não veda o som e está instalada em lugar impróprio, inadequado, de acesso a terceiros, como assistimos no cotidiano da atividade profissional. (BARROCO; TERRA, 2012, p. 206).

Assim, compreende-se ser de suma importância a Resolução $\mathrm{n}^{0}$ 493/2006, tendo em vista que estabelece o caráter essencial e obrigatório, por parte das instituições, da disponibilidade de espaço adequado para o atendimento profissional, de modo que seja garantida a privacidade do usuário naquilo que for revelado durante este processo (CFESS, 2006). Desta forma, reforça a importância, já preconizada no Código de Ética, do sigilo profissional ao estabelecer, em seu art. 3으, que "o atendimento efetivado pelo assistente social deve ser feito com portas fechadas, de forma a garantir o sigilo" (CFESS, 2006).

Esse instrumento soma-se a outros na defesa por melhores condições de trabalho, bem como na materialização do projeto ético-político no cotidiano profissional do assistente social, tendo em vista que "as forças políticas incidentes nas condições e relações de trabalho que circunscrevem o assistente social articulam um conjunto de mediações que interferem no processamento da ação e nos resultados individual e coletivamente projetados" (IAMAMOTO, 2008, p. 230 grifo das autoras).

Algumas pesquisas têm contribuído para analisar as repercussões das ações políticas do Conjunto CFESS/Cress no cotidiano de trabalho de assistentes sociais. Destacamos, aqui, parte da investigação de Ramos, Almeida e Morais $(2014)^{3}$ no que se refere à Resolução no 493/2006.

Esta pesquisa constatou que 80,6 \% das assistentes sociais participantes conheciam a referida resolução (RAMOS; ALMEIDA; MORAIS, 2014). Concordamos com a análise apresentada pelas autoras de que o amplo conhecimento da resolução ocorre por esta ter sido bastante divulgada entre este público, por meio de várias iniciativas, tais como: projetos de intervenção desenvolvidos pelas estagiárias, discussões nos fóruns de supervisores, visitas de fiscalização realizadas pelo Cress RN/Seccional de Mossoró, além do site do CFESS.

Ressaltamos que a luta política pelo conhecimento e efetivação desta resolução tem sido constante no âmbito do conjunto CFESS/Cress, através de visitas realizadas pelas agentes fiscais e/ou conselheiras às instituições, como disposto na resolução, verificando o espaço de trabalho e as condições em que o mesmo é desenvolvido. Além disso, dando visibilidade nas matérias publicadas nos sites e redes sociais do CFESS e dos Cress que expressam como essas estratégias e ações políticas são implementadas nos diversos espaços da categoria.

\footnotetext{
${ }^{3}$ A pesquisa intitulada A contribuição do CFESS na defesa da ética e dos direitos humanos: repercussão no cotidiano profissional das(os) supervisoras(es) de estágio foi realizada com 31 supervisoras de campo de estágio.
} 


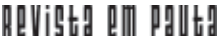

\} DESAFIOS DA CLASSE TRABALHADORA - SILVA, K. L.; RAMOS, S. R. \}

DOI: $10.12957 /$ rep.2015.21058

A parcela que desconhece a resolução provavelmente encontrase distanciada das iniciativas das entidades representativas da categoria que lutam em defesa da profissão e dos seus interesses. Compreendemos que este fato expressa, dentre outras questões, as repercussões das tentativas capitalistas de desorganização/fragmentação que incidem sobre a classe trabaIhadora, como forma de intensificar processos de alienação e dificultar a luta política que garante direitos sociais e do trabalho, no contexto de hegemonia do projeto do capital.

Com relação à repercussão da resolução no cotidiano de trabalho das supervisoras, a pesquisa em discussão revela que, entre as 25 conhecedoras da resolução, 15 alegam que a mesma repercutiu de forma positiva. Além disso, as entrevistadas colocam que, após a publicação da resolução, elas passaram a lutar por melhores condições de trabalho; muitas afirmam ter conseguido uma sala própria para o Serviço Social por conta da resolução. Uma delas declara: "Eu estar nesta sala hoje é fruto dessa resolução!" (RAMOS; ALMEIDA; MORAIS, 2014, p. 11).

A pesquisa referenciada revelou que a Resolução no 493/2006 teve significativa repercussão entre as profissionais, potencializando avanços no tocante à melhoria das condições de trabalho. Algumas, inclusive, alegam ter obtido avanços por meio da utilização da resolução como instrumento de luta, tal como a obtenção de sala própria para o Serviço Social. Esta conquista pode contribuir para ampliar as possibilidades de garantia da qualidade dos serviços prestados aos usuários do Serviço Social, com destaque para a garantia do sigilo profissional (RAMOS; ALMEIDA; MORAIS, 2014).

Compreendemos a importância da resolução para a categoria profissional, pois esta representa uma estratégia política de luta por melhores condições de trabalho nas últimas décadas, como outras ações importantes realizadas pelo conjunto CFESS/Cress, com destaque para a expressiva conquista da redução de jornada de trabalho. Esta última faz parte da agenda permanente de lutas do conjunto, tendo em vista que, além da batalha para a conquista da Lei $n^{\circ} 12.317 / 2010$, que garante 30h semanais para assistentes sociais, ainda travamos embates cotidianos para a sua efetivação nos mais variados espaços de atuação de assistentes sociais em todo o Brasil (BRASIL, 2010).

Nesse sentido, evidenciamos ser de suma importância para essa análise um resgate histórico, mesmo que de forma sucinta, da luta e conquista das $30 \mathrm{~h}$ semanais para assistentes sociais. Nesse ínterim, destacamos também a pesquisa que indica a importância de sua efetivação no cotidiano profissional, apontando essa conquista histórica como fruto da organização política da categoria no tocante à luta por condições de trabalho. 


\section{0h semanais para assistentes sociais: luta pela redução da jornada de trabalho}

Pensar a luta travada pela categoria de assistentes sociais, para a conquista e efetivação da Lei no $12.317 / 2010$, remete-nos ao contexto mundial de precarização da força de trabalho humana. Isso porque, mediante o processo de reestruturação produtiva, intensificado a partir dos últimos 40 anos, vem se configurando um crescente processo de intensificação da exploração do trabalho. Expressa-se nas altas jornadas de trabalho, na baixa remuneração salarial, na rotatividade profissional, na figura do trabalhador polivalente, entre outros, com grandes perdas dos direitos trabalhistas. Somase a isso o aumento do desemprego ou, ainda, a inserção via terceirização, precarizando os vínculos formais de trabalho. Como salienta lamamoto (2008, p. 233)

Esse contexto altera a demanda de trabalho do assistente social, modifica o mercado de trabalho, altera os processos de trabalho e as condições em que se realizam, nos quais os assistentes sociais ingressam enquanto profissionais assalariados. As relações de trabalho tendem a ser desregulamentadas e flexibilizadas. Verifica-se uma ampla retração dos recursos institucionais para acionar a defesa dos direitos e dos meios de acessá-los. Enfim, tem-se um redimensionamento das condições do nosso exercício profissional efetivado em condições de assalariamento.

Destarte, verifica-se que "a temática da superexploração e do desgaste físico e mental no trabalho profissional é um tema novo, pouco debatido, pouco pesquisado, portanto pouco conhecido pelo Serviço Social e seus trabalhadores, e que não apresenta acúmulo na literatura profissional" (RAICHELIS, 2011, p. 426).

Sabe-se que a jornada de trabalho é um dos principais elementos que constituem o aporte do que aqui está se chamando de condições e relações de trabalho. As altas cargas horárias de trabalho - a depender do tipo de atividade que se desenvolve - provocam um grande dispêndio de energia humana, muitas vezes afetando a saúde psíquica, física e social do trabalhador.

Embora, na realidade atual, os brasileiros trabalhem em média $44 \mathrm{~h}$ semanais ${ }^{4}$, sabe-se que isto é parte de uma conquista histórica da humanidade, fruto de muitas lutas da classe trabalhadora. Assim, a "instituição de uma jornada de trabalho é [...] o resultado de uma guerra civil de longa

\footnotetext{
${ }^{4}$ Não se pode esquecer que o movimento sindical brasileiro luta pelo estabelecimento de quarenta horas semanais em um país onde a jornada ainda é de quarenta e quatro horas, e que apenas seis profissões da área da saúde já possuem jornada igual ou inferior a 30h semanais (médicos, auxiliares laboratorista e radiologista, técnicos em radiologia, fisioterapeutas, fonoaudiólogos e terapeutas ocupacionais) (BOSCHETTI, 2011, p. 567).
} 


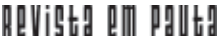

\} DESAFIOS DA CLASSE TRABALHADORA - SILVA, K. L.; RAMOS, S. R.

DOI: 10.12957/rep.2015.21058

duração, mais ou menos oculta, entre a classe capitalista e a classe trabalhadora" (MARX, 2008, p. 343).

Essa redução da jornada de trabalho, ao se configurar como conquista para a classe trabalhadora, contrapõe-se, por isso mesmo, ao sistema sociometabólico do capital. Desse modo, conjunturalmente observa-se um forte processo de correlações de forças, em que se percebe, por parte do capital, a tentativa de burlar essa e outras conquistas históricas desbravadas pela classe trabalhadora.

Nesta perspectiva, enfatiza Trindade (2011, p. 309) que "a proposta óbvia e racional de redução progressiva e universal da jornada de trabalho, com manutenção dos níveis salariais, contraria a lógica da acumulação do capital, ainda mais num mercado internacionalizado e tangido por concorrência feroz".

Nessa mesma lógica política, a categoria profissional de assistentes sociais, por meio do conjunto CFESS/Cress, enfrentou uma grande luta em defesa das 30h semanais, para assistentes sociais, sem redução salarial.

A luta pela redução da jornada de trabalho para as 30 horas semanais sem redução salarial foi construída no e pelo coletivo! Um coletivo [...] que, por quase três anos, mobilizou todas as forças e estratégias políticas para conquistar esse direito, [...]. E ele se realizou! Primeiro, com a aprovação do projeto de Lei da Câmara (PLC) 152/2008 no senado brasileiro [...]. (CFESS, 2011, p. 6).

Em um documento intitulado Porque o conjunto CFESS-Cress defende 30 horas de jornada semanal para assistentes social, encontramos explicitados vários motivos relacionados à defesa da aprovação deste projeto de lei. Dentre eles, destacam-se:

Defendemos a sanção do PLC 152/2008, que institui jornada de trabalho de 30 horas para assistentes sociais sem redução de salário, porque ele contribui na nossa luta por melhores condições de trabalho para assistentes sociais e se insere na luta pelo direito ao trabalho com qualidade para toda a classe trabalhadora, conforme estabelece nosso Código de Ética Profissional. (CFESS, 2010).

Sendo assim, verificou-se a necessidade da redução da jornada de trabalho do profissional do Serviço Social sem redução salarial. Isso demonstra a organização política da categoria profissional e sua luta referente aos direitos do trabalho, numa perspectiva que vai além da lógica corporativista, visando à defesa intransigente dos direitos da classe trabalhadora.

Desta feita, em 26 de agosto de 2010, após grande luta da categoria profissional, foi sancionada a Lei $\mathrm{n}^{\mathrm{o}}$ 12.317/2010, que dispõe sobre a duração do trabalho do assistente social - determinando que os contratos de trabalho dos profissionais brasileiros serão de, no máximo, 30h semanais sem haver redução salarial. 
A aprovação da jornada semanal de 30 horas sem redução salarial foi, inegavelmente, uma das mais importantes conquistas trabalhistas da categoria dos últimos anos, sobretudo porque se deu em um contexto de forte resistência política à redução da jornada de trabalho no Brasil. Essa conquista resultou de uma luta de quase três anos do CFESS, no âmbito do legislativo federal, fortalecida pelo mais emocionante ato público organizado pelo CFESS, ABEPSS e ENESSO nos últimos 20 anos. (BOSCHETTI, 2012, p. 32).

Outrossim, a luta pelas 30h semanais se constituiu numa das principais pautas do conjunto CFESS/Cress, na Gestão Atitude crítica para avançar na luta, que mobilizou toda a categoria profissional em busca da adesão no legislativo para a aprovação do "PL 30 horas" e, posteriormente, na busca pela sua sanção. Essa conquista foi muito importante para a categoria, contudo, muitos são os desafios para a efetivação da redução da carga horária, haja vista a dificuldade de ser materializada em uma sociedade regida pela lógica do capital. Configura-se, pois, como estratégia na busca por melhores condições de trabalho e contra a superexploração, "o que pode melhorar a saúde do(a) trabalhador(a) e ainda impor limites à exploração do trabalho pelo capital" (BOSCHETTI, 2011, p. 566).

Ainda, de acordo com Boschetti (2011, p. 567), "não por acaso, a implementação desse importante direito vem sendo contestado judicialmente pela Confederação Nacional da Saúde junto ao STF, e muitas instituições públicas resistem à sua implementação". Isto acontece pois muitas são tentativas do capital de barrar, na sociedade de classes, a efetivação de direitos que visam garantir melhor qualidade de vida para a classe trabaIhadora.

Nesse sentido, o conjunto CFESS/Cress, na Gestão Tempo de luta e resistência, deu continuidade à luta pela efetivação das 30h, tentando implementar outras estratégias na luta por melhores condições de trabalho. Assim,

Nas lutas em defesa das condições de trabalho, destaca-se nosso empenho na manutenção da conquista da jornada semanal de 30 horas sem redução salarial para assistentes sociais. Essa questão foi pauta de reuniões, audiências e debates. [...] Além disso, o Conselho Federal lançou o abaixo-assinado em defesa da lei 12.317/2010, contra a ação direta de inconstitucionalidade (ADIN) da Confederação Nacional de Saúde (CNS), e também organizou, em parcerias com os CRESS e Seccionais, dois Dias Nacionais de Luta pelas 30 horas, um em 2011 e outro em 2012, que contaram com mobilizações da categoria em todo o país. (RAMOS, 2012, p. 36-37).

Além disso, a Gestão Tempo de luta e resistência entrou com uma ação judicial contra o Ministério de Planejamento, Orçamento e Gestão (MPOG), para que seja garantida a efetivação da Lei no 12.317/2010 para assistentes sociais que trabalham no serviço público federal. 


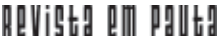

\} DESAFIOS DA CLASSE TRABALHADORA - SILVA, K. L.; RAMOS, S. R. \}

DOI: $10.12957 /$ rep.2015.21058

Dessa forma, enfatiza-se que "o CFESS repudia todas estas interpretações e ações que primam em não reconhecer direitos conquistados", e permanece na luta em defesa das 30h para assistentes sociais (RAMOS, 2012, p. 36-37). Sendo assim, embora a sanção da Lei no 12.317/2010 tenha ocorrido há cinco anos, grande tem sido a luta da categoria para efetivála em todo o país. Este fato é demonstrado pelas mobilizações que o conjunto CFESS/Cress, junto com toda a categoria profissional presente nos diversos espaços sócio-ocupacionais do país, vem implementando na busca por melhores condições de trabalho.

Nesse sentido, Delgado e Aquino (2014) apontam que a pesquisa realizada pela seccional do CRESS $6^{a}$ Região, através de visitas de fiscalização, em Juiz de Fora e região entre 2011 e 2012, revelam que o "terceiro setor" é o segundo maior espaço sócio-ocupacional que insere assistentes sociais no mercado de trabalho na referida cidade. Possui um percentual de $15,4 \%$, ficando atrás apenas da esfera pública municipal (60\%), superando, inclusive, as esferas públicas estadual $(11,4 \%)$ e federal $(5,2 \%)$. Esses dados expressam a expansão das instituições do chamado "terceiro setor", que, de acordo com Montaño (2007), se difunde no Brasil especialmente a partir da década de 1990 em diante ${ }^{5}$.

Desse modo, é relevante pesquisar quais são as condições e relações de trabalho dos assistentes sociais nesse espaço de intervenção profissional. Outrossim, aqui utilizamos resultados de uma pesquisa sobre condições e relações de trabalho de 14 assistentes sociais inseridas no "terceiro setor" em Mossoró (RN) (SILVA, 2013)6. Os dados revelam que, de 14 profissionais participantes, duas (14\%) não estão trabalhando de acordo com a Lei no 12.317; elas estão lotadas na mesma instituição (uma mencionou trabalhar $40 h$ e a outra, $35 h$ ).

Quando perguntada sobre o porquê da não redução da jornada de trabalho, Patrícia Pagú mencionou que "as assistentes sociais da instituição não sentiram a necessidade dessa redução" (SILVA, 2013, p. 147).

Já Indira Gandhi destacou a importância da lei para a categoria. Ela relacionou a ausência da necessidade de redução da carga horária devido ao fato de considerar-se, também, uma militante da instituição:

embora a gente considere ser importante pra categoria, ser uma luta da categoria para que tenhamos melhor qualidade de vida, pra que a gente tenha melhores condições de trabalho, porém aqui na entidade

\footnotetext{
${ }^{5}$ Ainda, acerca da expansão, áreas de atuação e do número de trabalhadores(as) que algumas instituições do "terceiro setor" ocupa, consultar IBGE, 2012.

${ }^{6} \mathrm{~A}$ pesquisa é intitulada Condições de trabalho e "terceiro setor": implicações contemporâneas para o serviço social. Trata-se de dissertação defendida em 2013, na Universidade Federal do Rio Grande do Norte (UFRN). Foi desenvolvida a partir do viés quanti-qualitativo, através da realização de pesquisa bibliográfica, documental e de campo, sendo submetida ao Comitê de Ética em Pesquisa (CEP) da UFRN; todas as participantes assinaram o Termo de Consentimento Livre e Esclarecido (TCLE), exigido pelo CEP. Assim, nas falas são usados nomes fictícios. Na pesquisa de campo utilizou-se a aplicação de questionários, além de ter sido realizada entrevista semiestruturada.
} 


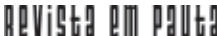

\} DESAFIOS DA CLASSE TRABALHADORA - SILVA, K. L.; RAMOS, S. R. \}

DOI: $10.12957 /$ rep.2015.21058

a gente não sentiu essa necessidade, a gente tem uma dinâmica de trabalho, a gente tem quarenta horas, quarenta e quatro, mas a gente só trabalha quarenta, e a gente também tem, como a gente é uma parte profissional e uma parte militante, a gente até acha que o tempo é pouco pra gente realizar tudo o que a gente acha que tem que ser realizado.

É comum a ideia da militância atrelada ao trabalho em algumas instituições do chamado "terceiro setor" ${ }^{7}$, mais especificamente em algumas ONGs, que, antes de vivenciar o processo de institucionalização, organizavam-se enquanto movimentos sociais. Com o advento da chamada "onguização", ocorre também a contratação profissional. Porém, prevalece nos sujeitos a identidade da militância política.

Nessa análise, cabe ainda destacar que o "terceiro setor" vem sendo difundido por empresas e intelectuais ligados à burguesia. Leva, dessa maneira, à reflexão sobre o porquê deste empenho em desenvolver ações institucionais voltadas para a (re)filantropização no trato da questão social. Assim como evidencia Montaño (2007, p. 53), "isso sinaliza clara ligação com os interesses de classe, nas transformações necessárias à alta burguesia". Há uma ideologia ligada à lógica capitalista que perpassa não apenas o conceito de "terceiro setor", mas todas as relações circunscritas no cerne do seu surgimento e expansão.

Ainda de acordo com a pesquisa, outras duas assistentes sociais (14\%) trabalham 20h semanais, e estão lotadas na mesma instituição (SILVA, 2013). Uma delas, Leila Diniz, possui outro vínculo empregatício. Acerca da redução da carga horária, a profissional disse que "não houve necessidade de discussão, pois a jornada é de 20 horas semanais". A outra assistente social já é aposentada e desenvolve um trabalho voluntário na instituição.

Assim, tem-se o estímulo à expansão de práticas como o voluntariado como um campo alternativo, no processo de expansão do chamado "terceiro setor", sendo o mesmo considerado, pelo discurso neoliberal, substituto do Estado, que é tido como insuficiente para o social (OLIVEIRA, 2005). Nesse sentido, a atuação dos assistentes sociais no "terceiro setor" se dá, muitas vezes, mediante a (re)filantropização, que se configura como uma das "novas" formas de intervir na questão social.

Ainda acerca da carga horária semanal, 10 profissionais (72\%) responderam que trabalham $30 \mathrm{~h}$ semanais em seus espaços de atuação (SILVA, 2013). Essas assistentes sociais estão lotadas em 4 das 6 instituições pesquisadas. Vale destacar, nessa análise, que Neves, Lima e Coimbra (2014), ao realizarem pesquisa com 7 assistentes sociais que trabalham em instituições do "terceiro setor", em Juiz de Fora, no ano de 2013, constataram

\footnotetext{
${ }_{7}$ Aqui, parte-se, sobretudo, de uma compreensão de que o "terceiro setor" existe na sociedade a partir de uma construção ideológica, sendo uma perspectiva reducionista no modo de abordar, interpretar e analisar a sociedade, dividindo-a em setores. Ainda, para um aprofundamento acerca do "terceiro setor", consultar Montaño (2007).
} 


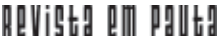

\} DESAFIOS DA CLASSE TRABALHADORA - SILVA, K. L.; RAMOS, S. R. \}

DOI: 10.12957/rep.2015.21058

que $85,71 \%$ dos assistentes sociais cumpriam carga horária entre 10 e $25 \mathrm{~h}$ semanais; os demais trabalham 30h. No entanto, as autoras chamam atenção para o fato de que essa "variação indica não só uma tendência de flexibilização das leis trabalhistas, mas também uma precarização dos vínculos de emprego" (NEVES; LIMA; COIMBRA, 2014, p. 6). Embora na Lei ${ }^{\circ}$ $12.317 / 2010$ esteja explícito que essa redução de carga horária deve acontecer sem a redução salarial, em alguns espaços a redução e variação da carga horária "envolve uma redução salarial, o que faz com que esses profissionais procurem outras possibilidades de emprego para completar os salários" (NEVES; LIMA; COIMBRA, 2014, p. 6).

Já na pesquisa realizada no "terceiro setor" em Mossoró, as profissionais consideram positiva a redução de carga horária, pois esta aconteceu sem a redução salarial (SILVA, 2013). Algumas profissionais destacam, inclusive, a repercussão da efetivação da Lei oํ 12.317/2010 na instituição, no trabalho profissional e na vida pessoal delas:

Repercutiu de forma positiva e foi aceita logo em um primeiro momento. (Cora Coralina).

É, a nossa instituição ela nunca teve nenhuma dificuldade, uma vez que a Lei foi aprovada imediatamente a gente foi beneficiada. (Ana Neri).

Quando a Lei foi implantada o CRESS de Natal procurou a entidade pra falar sobre a nova Lei, [...] foram analisar todas as nossas atribuições que eram pertinentes com o código de ética, com o projeto ético-político, tinha tudo a ver, tava tudo relacionado. E aí quando foi três de Janeiro de 2011 é nós passamos a trabalhar 30 horas, o [...] pagou o retroativo pelas horas trabalhadas que não estavam enquadradas pelas quarentas horas, que antes a agente trabalhava quarenta horas. E aí pra gente foi um grande avanço, nós [...] pudemos escolher o horário que a gente poderia trabalhar, são seis horas corridas. (Olga Benário).

As duas primeiras falas mostram que as instituições nas quais as profissionais trabalham passaram a efetivar a Lei $\mathrm{n}^{\circ}$ 12.317/2010 logo depois de ser sancionada. Já a fala de Olga Benário evidência que a lei passou a ser efetivada cinco meses depois de sua sanção, acontecendo logo após o CRESS-RN procurar a instituição. Esta, ao analisar as atribuições profissionais, garantiu não apenas a efetivação das 30h, mas também pagou o retroativo pelos meses que as assistentes sociais haviam trabalhado em regime de $40 \mathrm{~h}$ (SILVA, 2013).

As falas das profissionais revelam o quão importante é a efetivação dessa conquista para a categoria profissional. Dentre as respostas obtidas, destacam-se algumas referentes à melhoria da qualidade de vida, no tocante à existência de um tempo livre. 


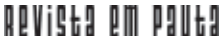

\} DESAFIOS DA CLASSE TRABALHADORA - SILVA, K. L.; RAMOS, S. R.

DOI: $10.12957 /$ rep.2015.21058

A instituição cumpriu a Lei no $12.317 / 2010$ com ganho na qualidade de vida, sem perda salarial. (Teresa de Calcutá).

Repercutiu na melhoria da qualidade de vida do profissional e não trouxe prejuízo para o profissional e instituição. (Mata Hari).

[...] foi muito bom porque essa diferença de horário né facilitou pra que a gente tivesse é, mais condições de resolver nossos problemas, nossa vida né, no tempinho que sobrou a gente resolver nossa vida. (Ana Neri).

Essa possibilidade pode repercutir de forma positiva para a qualidade de vida das profissionais, já que, na contemporaneidade, o contexto adverso do mundo do trabalho, ao submeter os trabalhadores a extenuantes horas de trabalho, despotencializa as dimensões da subjetividade humana, negando inclusive o direito ao lazer. É nesse sentido que a conquista das 30h busca combater altas jornadas de trabalho - motivo de adoecimento de muitos profissionais, em defesa de uma melhor qualidade de vida para os assistentes sociais.

Já com relação à não redução salarial, evidenciam-se algumas falas, quais sejam:

Valorizou significativamente o trabalho do assistente social, a hora trabalhada ficou mais valorizada, contribuindo para melhor desempenho e valorização do profissional diante das suas atribuições. (Joana D’Arc).

Eu continuo, realmente, recebendo o percentual que eu sempre recebi. (Romana Barros).

A profissional Joana D'arc destaca que as 30h valorizaram significativamente o trabalho profissional, dada a garantia da não redução salarial, o que faz dessa conquista algo histórico (SILVA, 2013). Ressalta-se, assim, que esse avanço é de suma importância, pois, "mesmo diante de uma conjuntura adversa à ampliação dos direitos do trabalho, os assistentes sociais conseguiram uma significativa vitória com a aprovação da jornada de 30 horas de trabalho sem redução salarial" (RAICHELIS, 2011, p. 435).

Sendo assim, a efetivação da redução da jornada de trabalho profissional é avaliada pela maioria das profissionais de maneira satisfatória. Elas reconhecem a importância dessa conquista para a categoria, cuja relevância também é valorizada pelas profissionais que destacaram não ter a necessidade da efetivação da lei. Este é o caso de Indira Gandhi que, apesar de atrelar o seu trabalho à militância política, destaca a importância de sua efetivação (SILVA, 2013).

Eu queria reforçar a importância dessa lei, queria reforçar a importância da lei para a maioria dos profissionais, das profissionais que 


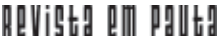

\} DESAFIOS DA CLASSE TRABALHADORA - SILVA, K. L.; RAMOS, S. R. \}

DOI: $10.12957 /$ rep.2015.21058

tem condições, é digamos assim, muitas das vezes insalubres, ou não tem as condições necessárias, as condições físicas, [...] e de sentir essa necessidade de buscar de que realmente essa lei seja efetivada em suas instituições, enquanto na nossa a gente não sentiu essa necessidade. Isso não significa dizer que daqui a pouco a gente não sinta essa necessidade e, realmente, busque esse direito que tá garantido, que foi uma conquista justa, é uma conquista e nós profissionais merecemos. (Indira Gandhi).

Esse entendimento e reconhecimento da importância das 30h por parte das profissionais é relevante para que a categoria possa permanecer articulada, no sentido de continuar se organizando politicamente na luta pela implementação da Lei $n^{\circ} 12.317 / 2010$. Isso é fundamental diante dos desafios que se apresentam para a sua efetivação, como a ADIN, mencionada anteriormente, impetrada pela Confederação Nacional da Saúde, além da normativa emitida pelo MPOG.

Por fim, destaca-se a fala de Frida Kahlo (SILVA, 2013). A assistente social enfatiza que a efetivação da Lei no 12.317/2010 foi

uma das maiores conquistas do conjunto CFESS/CRESS. A instituição adotou e inclusive as assistentes sociais são as únicas profissionais que trabalham 30 horas. (Frida Kahlo).

A partir da fala da profissional, infere-se que as entidades representativas da categoria, em especial o conjunto CFESS/Cress, têm se empenhado na luta contra a exploração do trabalho, engajando-se na conquista da garantia da lei em 2010 e em defesa de sua efetivação. Essa conquista "tece possibilidades para que assistentes sociais possam trabalhar em condições mais favoráveis para se refazerem subjetivamente dos impactos próprios de um tipo de trabalho que evidencia situações em que os usuários [...] estão subjetivamente despotencializados para viver" (SANTOS, 2010, p. 705-706).

\section{Algumas considerações para o debate e luta contínua}

A partir das reflexões apresentadas, consideramos que as estratégias políticas do conjunto CFESS/Cress em defesa de melhores condições de trabalho expressam a mediação da organização política da categoria para a defesa do projeto profissional, além de sua profunda vinculação com a luta anticapitalista na sociedade brasileira. Os desafios se ampliam diante da conjuntura de hegemonia do projeto do capital, que retira direitos, precariza o trabalho e fragmenta a classe trabalhadora.

Assim, concebemos que estas lutas desenvolvidas no âmbito do Serviço Social, através do conjunto CFESS/Cress, situam-se no contexto de 


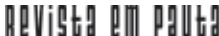

\} DESAFIOS DA CLASSE TRABALHADORA - SILVA, K. L.; RAMOS, S. R. \}

DOI: 10.12957/rep.2015.21058

produção e reprodução das relações sociais capitalistas e da prática histórica das classes sociais. Inserem-se, também, em um campo político de reforço à garantia de direitos, que venha a contribuir na ampliação das condições objetivas e subjetivas de vida para a classe trabalhadora.

De fato, ações políticas como a Resolução no 493/2006, bem como a Lei no 12.317/2010, são conquistas de fundamental importância para os assistentes sociais, especialmente a luta pela jornada de $30 \mathrm{~h}$ semanais sem redução salarial. Este é, "talvez [...], o movimento coletivo mais importante desses últimos anos em defesa de direitos do assistente social como trabalhador assalariado, mas que, como era de esperar, está sendo objeto de desconstrução por parte dos empregadores" (RAICHELIS, 2011, p. 435). Resta seguir na luta, traçando estratégias não somente para a efetivação da Lei no 12.317/2010, mas, também, em defesa de condições de trabalho que possibilitem garantir aos usuários melhor qualidade nos serviços prestados.

É nesta perspectiva que se inscrevem os investimentos do conjunto CFESS/Cress no que diz respeito ao debate e intervenção em relação às lutas por melhores condições de trabalho. Tais lutas apresentam-se como mediações estratégicas para a defesa de um projeto profissional vinculado à construção de um projeto societário sem exploração e opressões. 


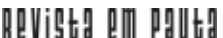

\} DESAFIOS DA CLASSE TRABALHADORA - SILVA, K. L.; RAMOS, S. R. \}

DOI: 10.12957/rep.2015.21058

\section{Referências}

ABREU, M. M. Serviço Social e a organização da cultura: perfis pedagógicos da prática profissional. São Paulo: Cortez. 2008.

ANTUNES, R. Os sentidos do trabalho: ensaios sobre a afirmação e a negação do trabalho. São Paulo: Boitempo Editorial. 1999.

BARROCO, M. L. S.; TERRA, S. H. (org.) Código de ética do/a assistente social comentado. São Paulo: Cortez. 2012.

BEHRING, E. R. Brasil em contra-reforma: desestruturação do Estado e perdas de direitos. São Paulo: Cortez. 2003.

BIHR, A. Da grande noite à alternativa: o movimento operário europeu em crise. São Paulo: Boitempo Editorial. 1999.

BORON, A. Os "novos leviatãs" e a polis democrática: neoliberalismo, decomposição estatal e decadência da democracia na América Latina. In: Pós-neoliberalismo II. Petrópolis: Vozes. 1999.

BOSCHETTI, I. Condições de trabalho e a luta dos(as) assistentes sociais pela jornada semanal de 30 horas. Revista Serviço Social e Sociedade, São Paulo, n. 107. 2011.

- Os intensos anos da atitude crítica para avançar na luta. Revista Inscrita, Brasília, n. 13. 2012.

BRASIL. Lei no 12.317 de 26 de agosto de 2010. Acrescenta dispositivo à Lei no 8.662 , de 7 de junho de 1993, para dispor sobre a duração do trabalho do assistente social. Publicada no DOU de 27 ago. 2010.

BRAZ, M. A hegemonia em xeque: projeto ético-político do Serviço Social e seus elementos constitutivos. Revista Inscrita, Brasília, n. 10. 2007.

CASTELO, R. O canto da sereia: social-liberalismo, novo desenvolvimentismo e supremacia burguesa no capital ismo dependente brasileiro. Revista Em Pauta: teoria social e realidade contemporânea, Rio de Janeiro, v. 11, n. 31. 2013.

CHESNAIS, F. A mundialização do capital. São Paulo: Xamã. 1996.

CONSELHO FEDERAL DE SERVIÇO SOCIAL (CFESS). Resolução n. 493. Dispõe sobre as condições éticas e técnicas do exercício profissional do assistente social. Brasília, 21 ago. 2006.

. Porque o conjunto CFESS-CRESS defende 30 horas de jornada semanal para assistentes sociais. Data: 16 ago. 2010. Disponível em: <http:/ /www.cfess.org.br/arquivos/documentofavoravel_plc152-2008_final.pdf>. Acesso em: 22 ago. 2010.

. Direito se conquista: a luta dos/as assistentes sociais pelas 30 horas semanais. Brasília: CFESS. 2011. 


\section{heVistg a p palth}

\} DESAFIOS DA CLASSE TRABALHADORA - SILVA, K. L.; RAMOS, S. R.

DOI: $10.12957 /$ rep.2015.21058

- O Conjunto CFESS/CRESS na luta por melhores condições de trabaIho para assistentes sociais. 2008. Disponível em: <http://www.cfess.org.br/ visualizar/noticia/cod/7>. Acesso em: 1 mar. 2015.

DELGADO, L. B.; AQUINO, I. G. de C. O mercado (precarizado) de trabaIho do assistente social em Minas Gerais e no Rio de Janeiro: condições de contratação, remuneração e salários indiretos. In: MOLJO, C. B.; SANTOS, C. M. dos (org.). Serviço Social e questão social: implicações no mundo do trabalho e no exercício profissional do assistente social em Juiz de Fora. Juiz de Fora: Ed. UFJF. 2014.

DIAS, E. F. Gramsci e a política hoje. Universidade e Sociedade, ano XI, n. 27, jun. 2002.

IAMAMOTO, M. Serviço Social em tempo de capital fetiche: capital financeiro, trabalho e questão social. São Paulo: Cortez. 2008.

HARVEY, D. Condição pós-moderna. São Paulo: Edições Loyola. 1999.

HELLER, A. O cotidiano e a história. Rio de Janeiro: Paz e Terra. 1989.

INSTITUTO BRASILEIRO DE GEOGRAFIA E ESTATÍ́STICA (IBGE). As fundações privadas e associações sem fins lucrativos no Brasil 2010. Estudos \& Pesquisas: informações econômicas, n. 20. 2012.

MANDEL, E. A crise do capital: os fatos e sua interpretação marxista. São Paulo: Editora Ensaio. 1990.

MARX, K. O capital: crítica da economia política. Livro I, volume 1. Rio de Janeiro: Civilização Brasileira. 2008.

MÉSZÁROS, I. Para além do capital. São Paulo: Boitempo. 2002.

MONTAÑO, C. E. Terceiro setor e questão social: crítica ao padrão emergente de intervenção social. São Paulo: Cortez. 2007.

MOTA, E.; AMARAL, A. Serviço Social brasileiro: cenários e perspectivas nos anos 2000. In: Serviço Social brasileiro nos anos 2000: cenários, pelejas e desafios. Recife: Editora UFPE. 2014.

NETTO, J. P. Das ameaças à crise. Revista Inscrita, Brasília, n. 10. 2007.

NEVES, V. S. de P.; LIMA, M. L.; COIMBRA, A. N. de S. Mercado e condições de trabalho: análise da inserção profissional nas organizações assistenciais do terceiro setor. In: ENCONTRO NACIONAL DE PESQUISADORES EM SERVIÇO SOCIAL. 2014. Natal. Anais: Lutas sociais e produção do conhecimento: desafios para o Serviço Social no contexto de crise do capital. Natal, Associação Brasileira de Ensino e Pesquisa em Serviço Social. 2014.

OLIVEIRA, L. M. de. A materialização do projeto ético-político do Serviço Social no cotidiano profissional em ONG's de Mossoró-RN. Monografia. Universidade do Estado do Rio grande do Norte, Mossoró. 2005.

PRÉDES, R (org.). Mercado de trabalho do serviço social: fiscalização e exercício profissional. Maceió: Edufal. 2002. 


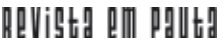

\} DESAFIOS DA CLASSE TRABALHADORA - SILVA, K. L.; RAMOS, S. R. \}

DOI: 10.12957/rep.2015.21058

RAICHELIS, R. O assistente social como trabalhador assalariado: desafios frente às violações de direitos sociais. Revista Serviço Social e Sociedade, São Paulo, n. 107. 2011.

RAMOS, S. R. CFESS em tempo de luta e resistência. Revista Inscrita, Brasília, n. 13. 2012.

RAMOS, S. R.; ALMEIDA, J.; MORAIS, D. M. J. A contribuição do CFESS na defesa ética e dos direitos humanos: repercussão no cotidiano profissional das(os) supervisoras(es) de estágio. In: ENCONTRO NACIONAL DE PESQUISADORES EM SERVIÇO SOCIAL. 2014. Natal. Anais: Lutas sociais e produção do conhecimento: desafios para o Serviço Social no contexto de crise do capital. Natal, Associação Brasileira de Ensino e Pesquisa em Serviço Social. 2014.

SANTOS, J. S. et al. Fiscalização do exercício profissional e projeto éticopolítico. Revista Serviço Social e Sociedade, São Paulo, n. 101. 2010.

SANTOS, S. M. de M. dos. O CFESS na defesa das condições de trabalho e do projeto ético-político profissional. Revista Serviço Social e Sociedade, São Paulo, n. 104. 2010.

SILVA, K. L. da. Condições de trabalho e terceiro setor: implicações contemporâneas para o serviço social. Dissertação. 2013. 180 f. (Mestrado) Centro de Ciências Sociais Aplicadas, Universidade Federal do Rio Grande do Norte, Natal. 2013.

TEIXEIRA, Francisco José S. O neoliberalismo em debate In: Neoliberalismo e reconstrução produtiva: as determinações do mundo do trabalho. São Paulo: Cortez; Fortaleza: Universidade Estadual do Ceará, 1998.

TERRA, S. Parecer jurídico $n^{\circ}$ 06/13. Dispõe sobre o uso de câmeras de filmagem, instaladas em salas de atendimento do Serviço Social; irregularidade de tal procedimento; Código de Ética do Assistente Social - quebra de sigilo; Constituição Federal - violação do direito à intimidade e à privacidade. São Paulo. 2013.

TRINDADE, J. D. de L. Os direitos humanos na perspectiva de Marx e Engels. São Paulo: Ôfega/Ômega; 2011.

Recebido em 31 de julho de 2015.

Aprovado para publicação em 01 de dezembro de 2015.

DOI: 10.12957/rep.2015.21058

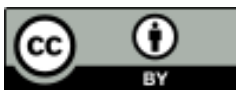

A Revista Em Pauta: Teoria Social e Realidade Contemporânea está licenciada com uma Licença Creative Commons Atribuição 4.0 Internacional. 